\title{
Glutamate Receptors Mediate TTX-Resistant Synchronous Activity in the Rat Hippocampus
}

\author{
Ben W. Strowbridge \\ Department of Neurosciences, Case Western Reserve University, Cleveland, Ohio 44106, and Departments of \\ Neurological Surgery and Physiology/Biophysics, University of Washington, Seattle, Washington 98195
}

\begin{abstract}
4-Aminopyridine (4-AP) is a well known convulsant that enhances the release of both excitatory and inhibitory neurotransmitters in the CNS. Low concentrations of 4-AP $(\sim 100 \mu \mathrm{M})$ readily induce synchronized discharges in the hippocampus that are blocked by tetrodotoxin (TTX), suggesting that they require $\mathrm{Na}^{+}$-dependent action potentials in addition to the enhanced release of neurotransmitters. However, in the present study we have found that higher concentrations of 4-AP (1 mM) in combination with $5 \mathrm{~mm}$ tetraethylammonium (TEA) induce spontaneous synchronized discharges in rat hippocampal slices that are resistant to blockade by TTX. These synchronous discharges are evident in field potential recordings, which progress from the hilus to CA1 at $0.023 \pm 0.002 \mathrm{~m} / \mathrm{sec}$ and in intracellular recordings from the hilar mossy cells and CA3 pyramidal cells. In some slices exposed to 4-AP and TEA,
\end{abstract}

Synchronized discharges, the hallmark of human epilepsy, can be induced readily in vitro by exposing brain slices to convulsant agents such as picrotoxin or bicuculline (Ayala et al., 1973; Schwartzkroin and Prince, 1978; Johnston and Brown, 1981; Wong and Traub, 1983). Experimental and theoretical studies of hippocampal slices disinhibited with these agents have suggested three factors that are critical to generate synchronized population discharges (Traub and Wong, 1982, 1983; Traub and Miles, 1991; Traub et al., 1993). First, the principal cells in the brain region must be capable of generating all-or-none responses. These intrinsic responses, typically recorded as structured bursts of action potentials (Wong and Prince, 1978), function to amplify and prolong excitatory synaptic inputs. Next, principal neurons need to be interconnected through recurrent axon collaterals. Recurrent excitatory connections were first suggested to be critical for synchronized discharges by Ayala et al. (1973) and have been demonstrated in the CA3 subfield of the hippocampus via both anatomical (Ishizuka et al., 1990; Li et al., 1993) and electrophysiological methods (MacVicar and Dudek, 1980; Miles and Wong, 1986). Finally, the strength of the synaptic connections between principal cells must be strong enough to enable "burst transduction"- the propagation of intrinsic all-or-none discharges from one principal cell to another (Traub and Wong, 1982; Traub and

\footnotetext{
Received March 22, 1999; revised April 30, 1999; accepted May 4, 1999.

This study was supported by National Institutes of Health (Grant NS33590) and the Epilepsy Foundation of America. B.W.S. is a Mt. Sinai Health Care Foundation Scholar. I thank Drs. Jeff Isaacson and Damir Janigro for helpful discussions and Shilpi Banerjee for constructive comments on this manuscript.

Correspondence should be addressed to Dr. Ben W. Strowbridge, Department of Neurosciences, Case Western Reserve University, 10900 Euclid Avenue, Cleveland, OH 44106-4975.

Copyright (C) 1999 Society for Neuroscience $\quad 0270-6474 / 99 / 195758-10 \$ 05.00 / 0$
}

smaller-amplitude asynchronous responses also were recorded. 4-AP-induced spontaneous discharges are blocked by $20 \mu \mathrm{M}$ DNQX and by $100 \mu \mathrm{M} \mathrm{Cd}{ }^{2+}$ but are resistant to blockade by either $25 \mu \mathrm{M}$ bicuculline or $25 \mu \mathrm{M}$ D-APV. These results suggest that the activation of postsynaptic AMPA receptors is necessary to produce TTX-resistant synchronized discharges. The laminar profile of field potentials recorded in CA3 and CA1 suggests that glutamate is released from axons of CA3 pyramidal cells despite the blockade of fast axonal $\mathrm{Na}^{+}$channels by TTX. Synchronous discharges may result from glutamate released at proximal recurrent collaterals after spontaneous $\mathrm{Ca}^{2+}$ spikes in CA3 pyramidal cells.

Key words: glutamate; synaptic transmission; hippocampus; epilepsy; axon conduction; AMPA receptors

Miles, 1991). When all three requirements are met, intrinsic all-or-none responses can percolate through a divergent network of principal cells; eventually, this process can engage the entire population in a synchronized all-or-none response.

Burst transduction is regulated tightly by feedforward inhibition. Local inhibitory interneurons function to prevent burst transduction in the hippocampus by truncating recurrent EPSPs generated by CA3 pyramidal cells (Miles and Wong, 1987). $\mathrm{GABA}_{\mathrm{A}}$ receptor antagonists reduce this disynaptic inhibition, enhancing the amplitude of recurrent EPSPs and facilitating burst transduction. Reduction in inhibition, however, is not required to generate synchronized bursts. Removal of $\mathrm{Mg}^{2+}$ from the extracellular solution results in a large enhancement of EPSPs and elicits population discharges in the hippocampus (Mody et al., 1987). Blockade of transient $\mathrm{K}^{+}$channels with 4-aminopyridine (4-AP) increases the amplitude of both IPSPs and EPSPs while promoting synchronized discharges in the hippocampus (Voskuyl and Albus, 1985; Rutecki et al., 1987; Chestnut and Swann, 1988, 1990; Ives and Jefferys, 1990).

A common feature of synchronized population discharges evoked through burst transduction is a reliance on tetrodotoxin (TTX)-sensitive $\mathrm{Na}^{+}$channels. TTX blocks synchronous population discharges elicited by 4-AP (Perreault and Avoli, 1991; Avoli et al., 1993) and disinhibition (Muller and Misgeld, 1991). The ability of TTX to suppress epileptiform discharges suggests that the propagation of fast $\left(\mathrm{Na}^{+}\right.$-based) action potentials through recurrent excitatory axons is required to generate synchronous population responses in the hippocampus. However, we now demonstrate that, on blockade of $\mathrm{K}^{+}$channels with 4-AP and tetraethylammonium (TEA), TTX-resistant synchronized discharges occur in both CA3 and CA1 subfields of the hippocam- 
pus. These responses are mediated synaptically and require the activation of non-NMDA glutamate receptors. The similarity of these TTX-resistant synchronous discharges to population discharges elicited by disinhibition suggests that the passive depolarization from intrinsic all-or-none responses may be capable of releasing glutamate from proximal recurrent axon collaterals and initiating $\mathrm{Ca}^{2+}$ spike transduction.

Some of these results have been presented previously in abstract form (Strowbridge, 1997a,b).

\section{MATERIALS AND METHODS}

Horizontal slices (300 $\mu \mathrm{m}$ thick) were prepared from the ventral hippocampus of 14- to 30-d-old Sprague Dawley rats with a vibratome (Oxford Laboratories, St. Louis, MO). Slices were incubated at $35^{\circ} \mathrm{C}$ for $30 \mathrm{~min}$ and then maintained at room temperature. Whole-cell patchclamp recordings were made on visualized hilar mossy cells and CA3 pyramidal neurons with an upright microscope equipped with infrared DIC optics (Axioskop FS, Carl Zeiss, Oberkochen, Germany) and an Axopatch 1C amplifier (Axon Instruments, Foster City, CA). Mossy cells were differentiated from other hilar neurons on the basis of cell body size and the presence of frequent large-amplitude EPSCs in voltage-clamp recordings (Buckmaster et al., 1993; Strowbridge and Schwartzkroin, 1996). During recordings the slices were superfused $(1.5-2 \mathrm{ml} / \mathrm{min})$ with warmed $\left(30^{\circ} \mathrm{C}\right)$ Ringer's solution equilibrated with $95 \% \mathrm{O}_{2} / 5 \% \quad \mathrm{CO}_{2}$. The Ringer's solution contained (in $\mathrm{mm}$ ): $124 \mathrm{NaCl}, 5 \mathrm{KCl}, 1.25$ $\mathrm{NaH}_{2} \mathrm{PO}_{4}, 1.3 \mathrm{MgSO}_{4}, 26 \mathrm{NaHCO}_{3}, 2.5 \mathrm{CaCl}_{2}$, and 10 dextrose. In most experiments, $1 \mu \mathrm{M}$ TTX was included to block $\mathrm{Na}^{+}$-based action potentials. Glycine $(10 \mu \mathrm{M})$ was added to the Ringer's solution in most experiments examining the actions of 6,7-dinitroquinoxaline-2,3-dione (DNQX) to prevent nonspecific effects of this antagonist on NMDA receptors. Patch-clamp electrodes (1.5-3 $\mathrm{M} \Omega$ resistance) used for voltage-clamp recordings contained (in $\mathrm{mM}$ ): $140 \mathrm{Cs}$-methanesulfonate, 8 $\mathrm{NaCl}, 10 \mathrm{HEPES}, 10$ EGTA, 10 phosphocreatine, $4 \mathrm{Mg}$-ATP, and 0.3 $\mathrm{Na}_{3}$-GTP, pH 7.3. The internal solution used for current-clamp recordings was identical except that $135 \mathrm{~mm} \mathrm{KMeSO}_{4}$ and $4 \mathrm{~mm} \mathrm{KCl}$ were substituted for the Cs-methanesulfonate. Series resistance was typically $<10 \mathrm{M} \Omega$ and was compensated routinely by $>80 \%$. The holding potential was $-80 \mathrm{mV}$ unless indicated otherwise. Field potentials were recorded with an Axoclamp 2A amplifier, using larger electrodes $(\sim 1 \mathrm{M} \Omega$ resistance) filled with Ringer's solution.

Both intracellular and extracellular recordings were filtered at $2 \mathrm{kHz}$, digitized at $5 \mathrm{kHz}$ (Labmaster DMA A/D converter, Scientific Solutions, Solon, $\mathrm{OH}$ ), and streamed to a hard disk with Axotape (Axon Instruments). Data were analyzed by custom-written software on an IBM PC. Most responses shown were averaged; a second field electrode was used to align the intracellular responses with the population responses. Response latencies were measured from the onset of field or intracellular response. A sharpened monopolar tungsten electrode was used to stimulate synaptic pathways. Receptor antagonists were obtained from Research Biochemicals (Natick, MA). Tetrodotoxin was obtained from Calbiochem (La Jolla, CA). All other compounds were obtained from Sigma (St. Louis, MO). Data are shown as mean \pm SEM.

\section{RESULTS}

Spontaneous population responses were recorded in the CA3 pyramidal cell layer after bath application of TEA $(5 \mathrm{~mm})$ and 4-AP (1 mM). These responses did not require fast $\mathrm{Na}^{+}$channels because they persisted in TTX $(1 \mu \mathrm{M}$; Fig. $1 A)$. Spontaneous TTX-resistant responses began several minutes after exposure to the $\mathrm{K}^{+}$channel blockers; potentials recurred with an average period of $9.3 \pm 1.2 \mathrm{sec}(n=15)$ for as long as the $\mathrm{K}^{+}$channel blockers were applied (often $>1 \mathrm{hr}$ ). Similar synchronized responses were observed in nearly all slices exposed to 4-AP, TEA, and TTX (75 of 81 slices). As shown in Figure $1 B$, no TTXresistant spontaneous population discharges were observed when either $\mathrm{K}^{+}$channel blocker was applied by itself. Lower concentrations of 4-AP (100-200 $\mu \mathrm{M})$ in combination with TEA $(5 \mathrm{mM})$ also failed to generate spontaneous population activity $(n=4)$. In the presence of both 4 -AP $(1 \mathrm{~mm})$ and TEA $(5 \mathrm{~mm})$, the time course of the spontaneous population response paralleled a large inward current recorded in CA3 pyramidal cells (mean amplitude $=3360 \pm 619 \mathrm{pA} ; n=8)$ and hilar mossy cells $(1900 \pm 503$ pA; $n=12$; Fig. $1 C$ ). The time course of the intracellular and field responses was similar and biphasic; the average duration of the spontaneous responses was $391 \pm 25 \mathrm{msec}(n=12)$. Intracellularly recorded responses often appeared quite noisy, suggesting that the large inward current resulted from the summation of many smaller synaptic responses.

We next tested whether spontaneous population responses evoked by $\mathrm{K}^{+}$channel blockers were mediated by incompletely blocked $\mathrm{Na}^{+}$current. As shown in Figure $1 D$, we verified that this concentration was sufficient to block completely the field EPSP evoked by mossy fiber stimulation $(n=3)$. This evoked synaptic response was not restored by the addition of $1 \mathrm{~mm}$ 4-AP and $5 \mathrm{~mm}$ TEA, although spontaneous population discharges were recorded through the same electrode. The evoked response was restored only on washout of TTX and the $\mathrm{K}^{+}$channel blockers (Fig. 1D, Wash). In three slices bathed in $\mathrm{K}^{+}$channel blockers, increasing the concentration of TTX from 1 to $3 \mu \mathrm{M}$ did not affect the amplitude or frequency of spontaneous population responses (data not shown). These results confirm that TTX blocked the propagation of fast $\left(\mathrm{Na}^{+}\right.$-based) action potentials in this pathway in the hippocampus and suggest that spontaneous population discharges do not require TTX-sensitive $\mathrm{Na}^{+}$ channels.

We examined the propagation of spontaneous population responses in different regions of the hippocampus using dual field electrode recordings. As shown in Figure $2 A$, spontaneous discharges could be recorded nearly simultaneously throughout CA3c. Spontaneous population responses typically were initiated near the proximal region of CA3c. In six paired recordings in CA3, spontaneous responses always occurred first in the electrode closest to the hilus. We estimated the propagation velocity of the spontaneous discharges by increasing the separation between two field electrodes in CA3 in uniform steps $(200 \mu \mathrm{m})$ and plotting the latency of the responses versus the electrode separation (Fig. $2 C$ ). The average propagation velocity, estimated from the slope of this relationship, was $0.023 \pm 0.002 \mathrm{~m} / \mathrm{sec}$ ( $n=6$ slices). This velocity is approximately six times slower than the propagation of (TTX-sensitive) synchronized discharges in disinhibited hippocampal slices $(0.15 \mathrm{~m} / \mathrm{sec}$; Miles et al., 1988). The sensitivity of propagation velocity to changes in temperature can be used to differentiate between conduction relying on active conductances (e.g., regenerative $\mathrm{Na}^{+}$or $\mathrm{Ca}^{2+}$ spikes) and the passive spread of ions through the extracellular space. We found that the propagation velocity of TTX-resistant spontaneous discharges in CA3 was dependent on temperature $\left(Q_{10}=2.1 \pm 0.1 ; n=3\right)$, suggesting that these synchronized discharges propagate actively throughout CA3.

The field potential recorded in the CA3 pyramidal cell body layer consists of at least two components. These components can be separated by examining the laminar profile of the TTXresistant spontaneous discharges (Fig. 2C). The earliest response recorded in the cell body layer was a negative field potential that increased in amplitude as the recording electrode was moved toward stratum oriens, was nulled near stratum lucidum, and reversed polarity in stratum radiatum. This laminar pattern suggests that these responses are not initiated by activity in the mossy fiber pathway because the field responses evoked from this pathway should be maximal in stratum lucidum (compare with Fig. $1 D)$. Rather, this laminar pattern is consistent with activity in the 

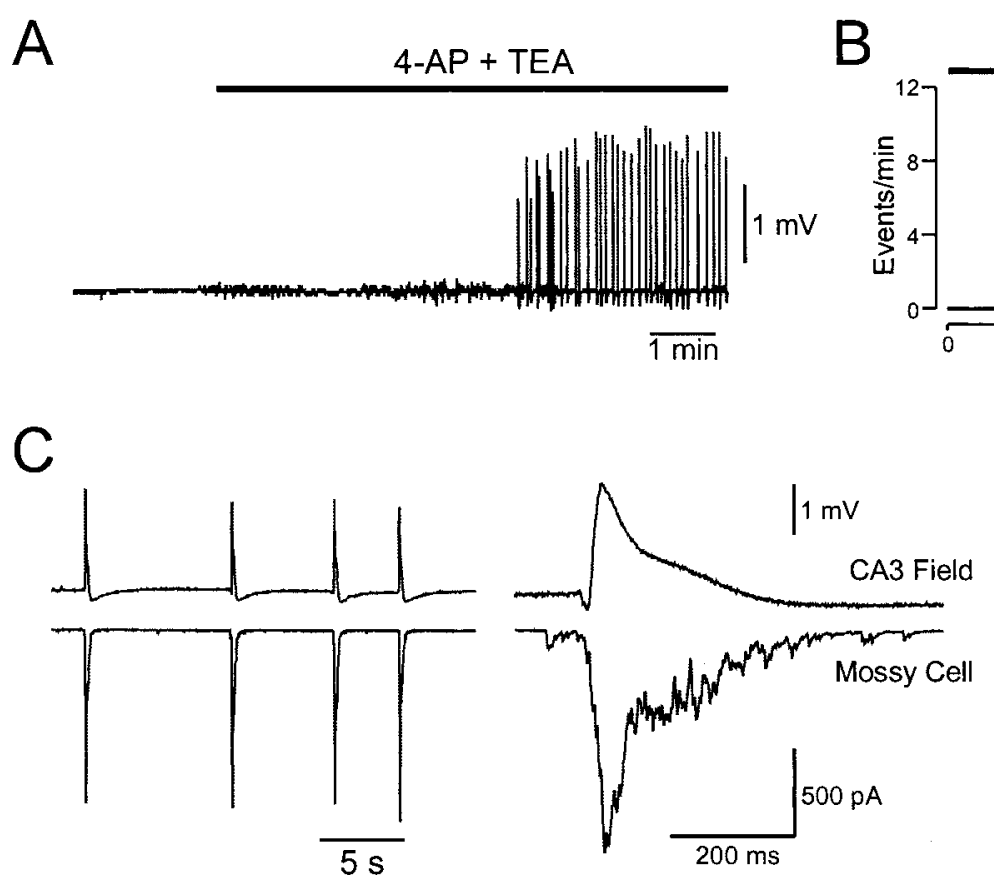

D

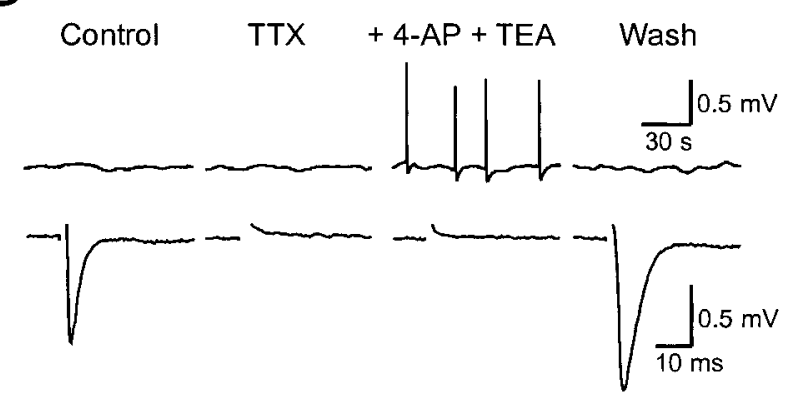

Figure 1. Potassium channel blockade evokes synchronous discharges. A, Field potential recording in CA3c. Spontaneous positive field potentials are recorded after coapplication of 4-AP $(1 \mathrm{mM})$ and TEA $(5 \mathrm{~mm})$. All records were obtained in the presence of $1 \mu \mathrm{M}$ TTX. $B$, Plot of the effect of potassium channel blockers on spontaneous discharge frequency in TTX. No discharges occurred when 4-AP was applied by itself. Spontaneous responses also ceased when TEA was applied alone and returned to control frequency when both potassium channel blockers were reapplied. $C$, Spontaneous field potentials (top traces) are correlated with large inward currents recorded in hilar mossy cells (bottom traces) and CA3 pyramidal cells (data not shown). The right panel shows a single response at a faster sweep speed. The large intracellular response is composed of the summation of many smaller-amplitude EPSCs. $D$, Simultaneous recordings of spontaneous activity and field EPSP evoked by electrical stimulation of mossy fibers. TTX (1 $\mu \mathrm{M})$ completely blocks the evoked EPSP. No spontaneous activity is recorded before or after TTX application. However, after the coapplication of 4-AP and TEA, spontaneous population discharges are present in the field recordings, whereas the evoked EPSP remains blocked. After the washout of all drugs the evoked EPSP is restored and the spontaneous discharges are abolished.

CA3 recurrent excitatory pathways. These connections are known to terminate on the basal dendrites of CA3 pyramidal cells and would be expected to generate a negative field potential in stratum oriens when activated (Li et al., 1993). The second component, the large positive wave in stratum pyramidale, decreased in amplitude in both stratum oriens and stratum lucidum and reversed polarity in stratum radiatum. The negative wave recorded in stratum radiatum likely reflects intrinsic regenerative currents in the apical dendrites of $\mathrm{CA} 3$ pyramidal cells that are triggered by excitatory synaptic inputs. A similar laminar pattern of field potentials was observed in seven other hippocampal slices exposed to 4-AP, TEA, and TTX.

The propagation of synchronized discharges through the hippocampus was examined by using dual field potential recordings. As illustrated in Figure 2D, one field electrode was fixed in the pyramidal cell layer of CA3b while the second electrode was moved to different hippocampal subfields. In all of the slices that were tested, large-amplitude field potentials could be observed throughout the CA3 region. Smaller field responses also were seen in the dentate gyrus in $50 \%$ of the slices (four of eight). These field potentials appear to originate from activity in hilar neurons because we recorded large periodic inward currents in all mossy cells tested ( $n=36$; see Fig. 1 ). By contrast, no synaptic inputs were observed in intracellular recordings from dentate granule cells ( $n=4$; data not shown) during synchronized discharges that originated in CA3. We often also observed the propagation of TTX-resistant discharges to CA1 (eight of nine slices). The amplitude of the population responses recorded in
CA1 generally was smaller than the responses recorded in CA3 (Fig. 2D). The shape of these field potentials varied considerably from slice to slice; often field response recorded in stratum radiatum in CA1 consisted of two negative waves rather than the biphasic response recorded in the apical dendritic zone in CA3. Synchronized responses were either absent (Fig. 2D) or extremely small in the subiculum.

The analysis of the two components of the spontaneous field potentials suggests that an excitatory synaptic input triggers a depolarizing regenerative response in a population of CA3 pyramidal cells. To test this hypothesis, we recorded intracellular responses of hilar and CA3 neurons under voltage-clamp control during spontaneous population discharges. At hyperpolarized holding potentials a large inward current developed that paralleled the field response (Fig. 3A). In eight neurons that were tested, the spontaneous current response reversed polarity near 0 $\mathrm{mV}$ (Fig. 3B), suggesting that it was mediated by synaptically released glutamate. In CA3 pyramidal cells the time course of the decay of the spontaneous currents was noticeably slower at depolarized holding potentials, suggesting the involvement of voltage-sensitive NMDA receptors. Both intracellular and field responses were sensitive to low concentrations of $\mathrm{Cd}^{2+}$, a nonselective blocker of voltage-sensitive calcium channels $(n=7$; Fig. $3 C$ ). These results are consistent with the hypothesis that glutamate is released actively during TTX-resistant synchronized discharges.

Glutamate and GABA receptor antagonists were used to test directly the role of these transmitters in the spontaneous dis- 

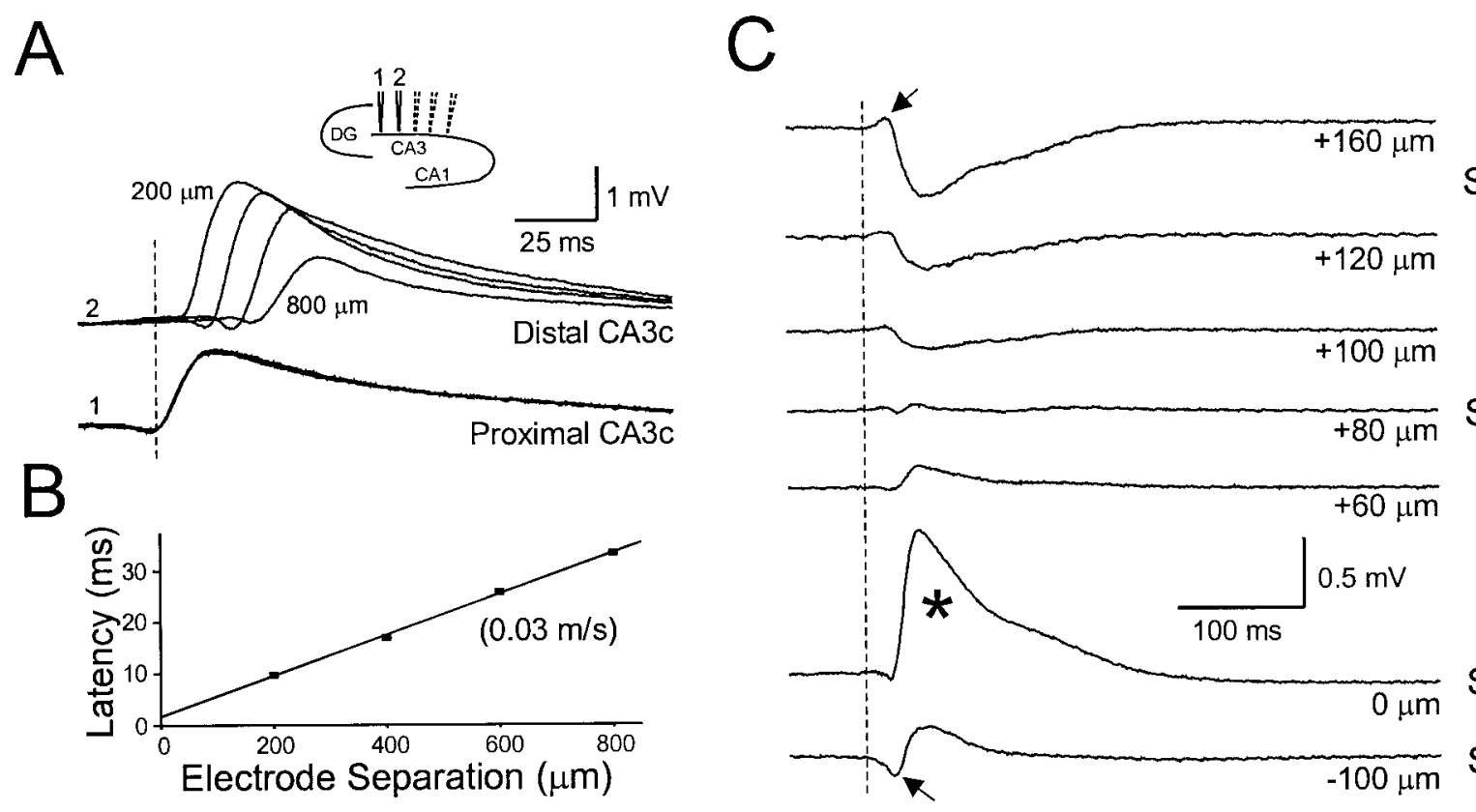

Str. radiatum

D

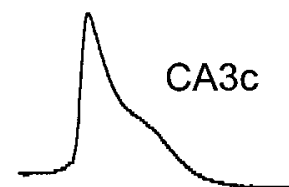

Hilus

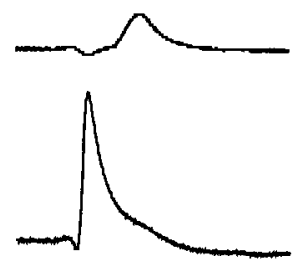

CA1 pcl
CA1 rad

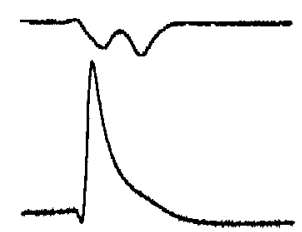

Str. pyramidale Str. oriens
Str. Iucidum

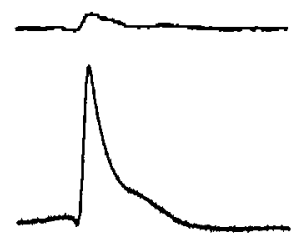

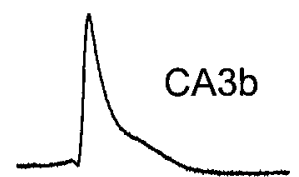

Figure 2. Propagation of synchronous discharges. $A$, Simultaneous recording of spontaneous discharges from two sites in CA3, separated by 200, 400, 600 , or $800 \mu \mathrm{m}$. Spontaneous discharges always were recorded first at the site closest to the dentate hilus (Proximal CA3c). B, Plot of the latency of the response at the distal site versus the separation between the recording electrodes. The propagation velocity estimated from the slope of this relationship was $0.03 \mathrm{~m} / \mathrm{sec}$ in this example. $C$, Laminar profile of spontaneous field recordings in CA3. Recordings at different laminar positions were obtained sequentially; responses from a second, fixed electrode (data not shown) were used to register each response. The initial, negative phase of the field response was largest in str. oriens and reversed polarity in str. radiatum (arrows). The later positive wave was largest in str. pyramidale and reversed polarity in str. lucidum (asterisk). The estimated distance from the recording site to the center of str. pyramidale is indicated under each record. $D$, Simultaneous field potential recordings in CA3b str. pyramidale and neighboring regions. Spontaneous discharges appeared to be initiated in CA3c and then propagated throughout CA3b-CA3a. A smaller field response was observed in the dentate hilus; no response was seen in subiculum or in dentate granule cells (data not shown). Responses in CA1 pyramidal cell layer $(C A 1 \mathrm{pcl})$ typically were very small, with the positive wave delayed by $100-200$ msec relative to the response in CA3. Responses in str. radiatum (CA1 rad) also differed greatly between the CA1 and CA3 subfields. All experiments were performed in 4-AP $(1 \mathrm{mM})$, TEA $(5 \mathrm{mM})$, and TTX $(1 \mu \mathrm{M})$.

charges (Fig. 4). Bath application of the $\mathrm{GABA}_{\mathrm{A}}$ receptor antagonist bicuculline methiodide (BMI; $25 \mu \mathrm{M})$ had no effect on the frequency of the spontaneous field potentials recorded in CA3 (94.1 $\pm 3.9 \%$ of control; $n=4)$. Blockade of NMDA-type glutamate receptors with D-2-amino-5-phosphopentanoic acid (DAPV; $25 \mu \mathrm{M}$ ) also had no effect on the frequency of spontaneous discharges $(84.4 \pm 12.0 \%$ of control; $n=3)$ but slightly reduced the amplitude of the field potentials recorded in CA3 in some experiments (Fig. 4A). The initiation of synchronized bursts also did not depend on NMDA receptors, because 4-AP and TEA were able to elicit field discharges even in the presence of D-APV (25 $\mu \mathrm{M})$ in three of four slices tested (data not shown). By contrast, blockade of non-NMDA glutamate receptors with DNQX $(20 \mu \mathrm{M})$ reversibly halted the spontaneous population responses ( $n=10$; Fig. $4 A$ ), suggesting that non-NMDA receptors are required to generate synchronized discharges. Results from experiments that used these receptor antagonists are summarized in Figure 4D.

Central neurons express non-NMDA glutamate receptors both postsynaptically - where they mediate most excitatory postsynaptic responses (Collingridge and Lester, 1989) — and presynaptically (Chittajallu et al., 1996; Rodriguez-Moreno et al., 1997), where they modulate transmitter release. Recent studies in the hippocampus suggest that different subtypes of non-NMDA glutamate receptors are expressed on pre- and postsynaptic structures. Kainate receptors appear to modulate glutamate release via presynaptic autoreceptors (Chittajallu et al., 1996), whereas unitary postsynaptic EPSPs in hippocampal pyramidal cells are mediated by AMPA receptors (Vignes and Collingridge, 1997). We used the recently developed AMPA receptor-selective antagonist GYKI 52466 (Zorumski et al., 1993) to test whether DNQX blocked spontaneous discharges by acting on presynaptic gluta- 
A

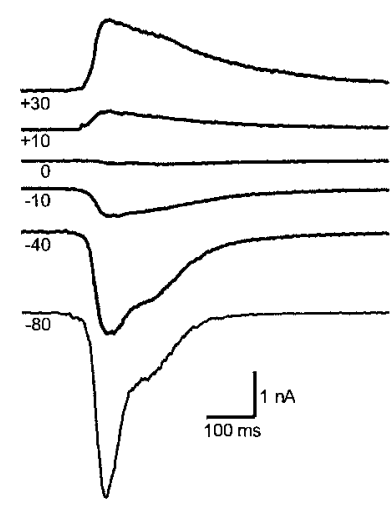

B

C

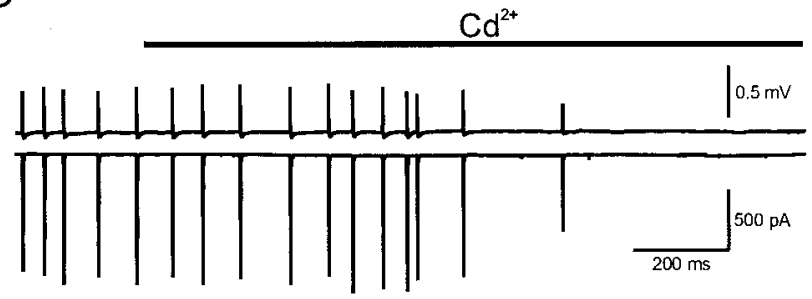

Figure 3. Reversal potential of synchronized discharges. $A$, Intracellular responses to synchronized discharges in a hilar mossy cell under voltageclamp control. Responses were aligned by using a field response recorded simultaneously (data not shown). $B$, Plot of intracellular response amplitude versus holding potential for the cell shown in $A$. The reversal potential of the synchronized discharges was estimated by linear regression (line) to be $2 \mathrm{mV}$. C, Cadmium $(100 \mu \mathrm{M})$ blocks synchronized discharges. Shown are a simultaneous field potential recording in CA3c (top trace) and voltage-clamp recording from a hilar mossy cell (bottom trace).

mate receptors. As with DNQX, we found that GYKI 52466 (25 $\mu \mathrm{M})$ completely blocked spontaneous discharges $(n=3$; Fig. $4 D)$, suggesting that only AMPA receptors-presumably located on the postsynaptic neuron - are required to generate TTX-resistant population discharges.

We next used the large NMDA component of the response to determine whether presynaptic terminals continue to release glutamate actively after the synchronized population discharges are halted with DNQX. Such a scenario might be expected if the $\mathrm{K}^{+}$ channel blockers increased the excitability of presynaptic terminals sufficiently to promote spontaneous $\mathrm{Ca}^{2+}$ spikes in glutamatergic terminals. At the normal resting potential, spontaneous EPSCs generated by ectopic $\mathrm{Ca}^{2+}$ spikes in presynaptic terminals would be blocked by DNQX but should be apparent as NMDAmediated currents at depolarized holding potentials. To test this hypothesis, we first verified that there was a significant NMDA component to the response by applying D-APV while holding a CA3 pyramidal cell at $+40 \mathrm{mV}$. As shown in Figure $4 B$, blockade of NMDA receptors by D-APV typically reduced the periodic spontaneous responses by $\sim 300 \mathrm{pA}$ when the membrane potential was held at a positive potential (to relieve the voltage-dependent blockade of NMDA receptors by $\mathrm{Mg}^{2+}$ ). After washout of D-APV, DNQX $(20 \mu \mathrm{M})$ was applied to stop the synchronized discharges. DNQX completely blocked all large-amplitude spontaneous synaptic currents even at this depolarized membrane potential ( $n=5$; Fig. $4 C$ ), suggesting that spontaneous discharges do not originate from ectopic $\mathrm{Ca}^{2+}$ spikes in presynaptic terminals. Increasing the overall excitability of the slice by raising extracellular $\mathrm{K}^{+}$to $15 \mathrm{~mm}$ also did not elicit synchronized synaptic responses in the presence of DNQX $(n=4$; data not shown). These results suggest that activity in polysynaptic circuits, rather than ectopic $\mathrm{Ca}^{2+}$ spikes in individual presynaptic terminals, is required to generate synchronized discharges.

The apparent requirement for postsynaptic AMPA receptors suggests that these spontaneous population responses are mediated by synaptic interactions. Dual intracellular recordings demonstrated that CA3 pyramidal cells innervate each other (MacVicar and Dudek, 1980; Miles and Wong, 1986). This recurrent excitation is the basis of synchronized discharges observed after treatment with $\mathrm{GABA}_{\mathrm{A}}$ receptor antagonists (for review, see Traub and Miles, 1991). Does the same recurrent excitatory mechanism underlie TTX-resistant synchronized discharges? One sensitive test for this type of network activity is to block AMPA receptors partially and determine whether the frequency of spontaneous discharges is reduced before the responses fail completely. In four slices low concentrations of DNQX (4 $\mu \mathrm{M})$ slowed the frequency of spontaneous TTX-resistant discharges (to $34.3 \pm 13.0 \%$ of control frequency; Fig. $4 D$ ), suggesting that polysynaptic interactions are involved in generating synchronized discharges.

Although the predominant effect of 4-AP and TEA was the production of large-amplitude, synchronized discharges in the hippocampus, we also observed frequent barrages of synaptic responses after $\mathrm{K}^{+}$channel blockade. An example of these responses is shown in Figure $5 A$; four small trains of EPSCs can be seen in addition to the large synchronized discharge. Although the time course of these small-amplitude discharges is similar to synchronized discharges recorded in the same neuron, no field response was observed (Fig. 5B), suggesting that these responses are generated asynchronously. Asynchronous responses were blocked by DNQX (data not shown) and by $100 \mu \mathrm{M} \mathrm{Cd}^{2+}$ (Fig. $5 C$ ), suggesting that they are composed of glutamatergic EPSCs. These synaptic barrages were not observed when TTX was applied without 4-AP and TEA. The high probability of observing an asynchronous response immediately before a synchronized discharge (Fig. 5D) suggests that the two types of responses may be related.

Why are both 4-AP and TEA required to produced synchronized discharges? Under current-clamp conditions, depolarizing currents steps lead to regenerative calcium spikes after exposure to TEA with or without 4-AP (Fig. 6). The large spontaneous synaptic currents observed in voltage-clamp recordings from CA3 pyramidal cells appear to trigger intrinsic all-or-none calcium spikes in CA3 neurons. As shown in Figure 6 $\mathrm{A}$, several inflections can be observed on the decay of both intrinsic and synaptically evoked responses. These inflections are minimized as the membrane is hyperpolarized (Fig. 6B) and may reflect the cessation of regenerative calcium current at different dendritic locations (Reuveni et al., 1993). As shown in Figure 6C, 4-AP lowers the current threshold for triggering regenerative calcium spikes without dramatically altering the spike itself. By lowering the threshold for triggering a calcium spike, 4-AP may enhance the probability of a spontaneous calcium spike in one CA3 cell, to trigger a calcium spike in a second, postsynaptic neuron. In addition, 4-AP also would be expected to block transient $\mathrm{K}^{+}$channels in CA3 pyramidal cell axons (Debanne et al., 1997).

\section{DISCUSSION}

This study reports a novel form of synchronized activity in the hippocampus that does not require fast $\mathrm{Na}^{+}$channels. We found 
A

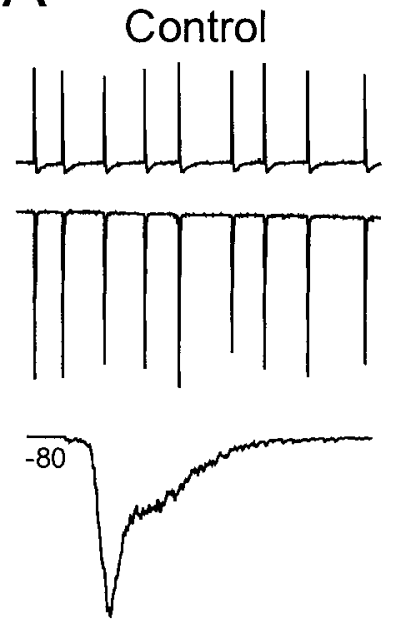

B

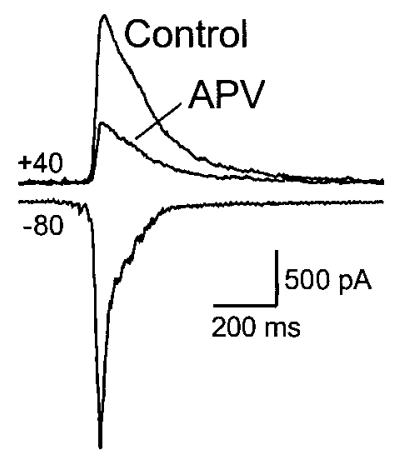

$B M I+A P V$
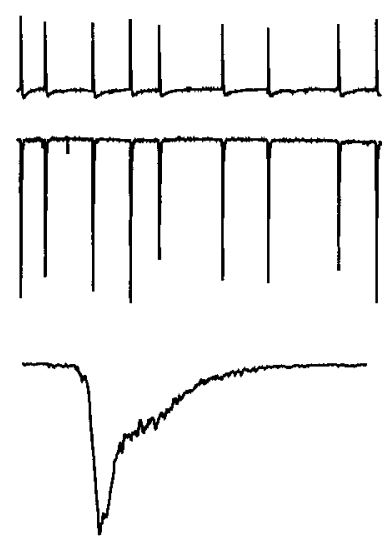

C

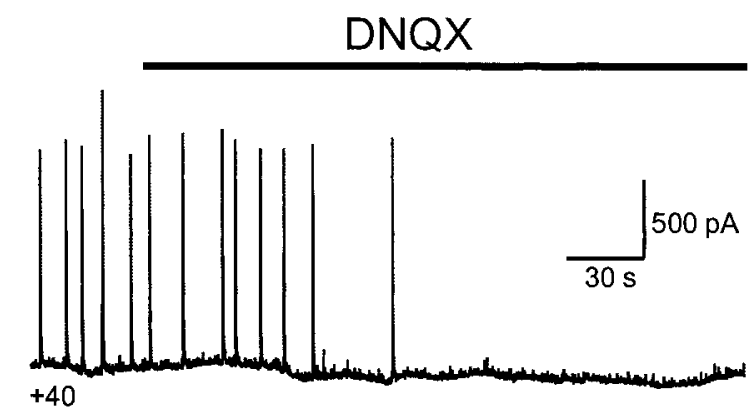

$+D N Q X$
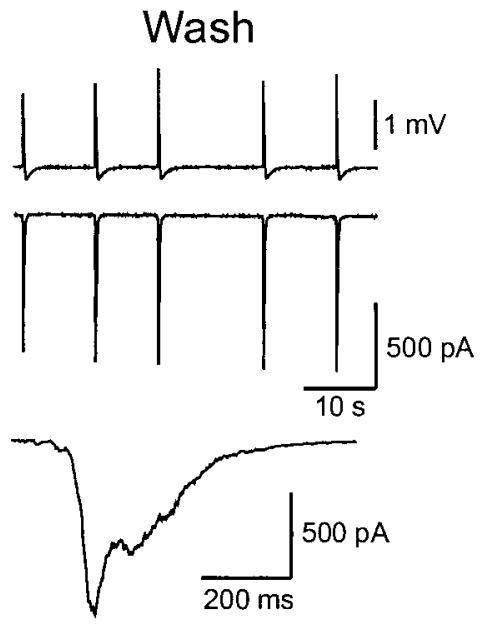

D

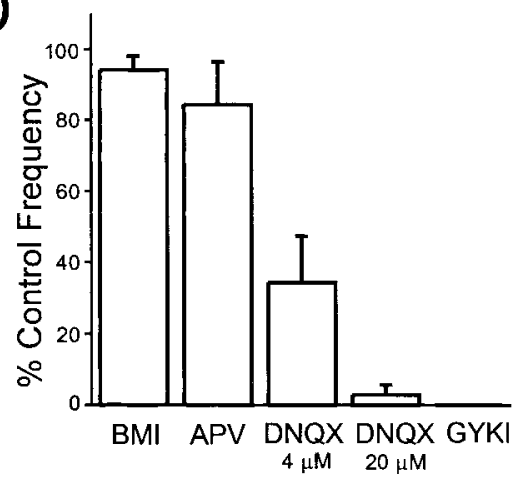

Figure 4. Synchronous discharges require AMPA receptors. $A$, Simultaneous field potential recordings in CA3c (top traces) and voltage-clamp recording

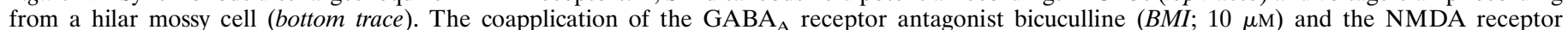
antagonist D-APV $(25 \mu \mathrm{M})$ fails to block synchronous discharges. The addition of the non-NMDA receptor antagonist DNQX (20 $\mu \mathrm{M})$ reversibly blocks both field and intracellular spontaneous responses. Example responses are shown below each set of traces. $B$, Intracellular recording of synchronous responses from a CA3c pyramidal cell held at -80 and $+40 \mathrm{mV}$. The response at $+40 \mathrm{mV}$ is blocked partially by D-APV (25 $\mu \mathrm{M})$ indicating that, at positive membrane potentials, synchronous responses are attributable to the coactivation of both NMDA and non-NMDA glutamate receptors. $C$, After washout of D-APV, synchronous responses recorded at $+40 \mathrm{mV}$ are blocked completely by DNQX $(20 \mu \mathrm{M})$, suggesting that a potassium channel blockade does not evoke pulsatile release of glutamate from axon terminals in the absence of the activation of postsynaptic glutamate receptors. $D$, Summary of the effects of bicuculline, D-APV, low and high concentrations of DNQX, and the AMPA receptor-selective antagonist GYKI 52466 (25 $\mu$ M) on spontaneous discharge frequency. No spontaneous responses were observed in three neurons exposed to GYKI.

that high concentrations of 4-AP, in combination with TEA, induce large spontaneous inward currents in hilar mossy cells and CA3 pyramidal cells and that these responses persist in TTX. The prominent field potential in CA3 associated with these glutamatergic responses demonstrates that these spontaneous discharges are synchronous. In some experiments we also observed smalleramplitude responses induced by $\mathrm{K}^{+}$channel blockade that had similar time courses but that were not associated with a field potential.

\section{Multiple forms of synchronized activity induced by 4-AP}

4-Aminopyridine has been used widely to promote spontaneous synchronous activity in the hippocampus. Low concentrations of 4-AP (50-100 $\mu \mathrm{M})$ readily induce interictal-like spontaneous discharges in populations of CA3 pyramidal cells in vitro (Voskuyl and Albus, 1985; Rutecki et al., 1987; Chestnut and Swann, 1988, 1990; Ives and Jefferys, 1990; Perreault and Avoli, 1991, 1992). These synchronous discharges are associated with the depolarization of CA3 pyramidal cells and are abolished by antagonists of non-NMDA glutamate receptors (Perreault and Avoli, 1991) but are unaffected by antagonists of NMDA receptors (Avoli et al., 1993). 4-AP also can synchronize inhibitory interneurons in both CA3 and CA1 regions of the hippocampus, generating giant IPSPs in pyramidal cells that are resistant to a blockade by glutamate receptor antagonists (Segal, 1987; Michelson and Wong, 1994). However, both synchronous excitatory (Perreault and Avoli, 1991; Avoli et al., 1993) and inhibitory (Segal, 1987) responses evoked by low concentrations of 4-AP are blocked completely by TTX, suggesting that these forms of synchronized activity require fast $\mathrm{Na}^{+}$-dependent action potentials.

The synchronized responses described in this report appear to represent a novel form of population activity in the hippocampus. The most striking difference between these discharges and those elicited by lower concentrations of $\mathrm{K}^{+}$channel blockers or $\mathrm{GABA}_{\mathrm{A}}$ receptor antagonists is their sensitivity to TTX. Although TTX completely abolishes spontaneous discharges evoked by disinhibition (Muller and Misgeld, 1991) and 4-AP (Perreault and Avoli, 1991; Avoli et al., 1993), synchronous re- 


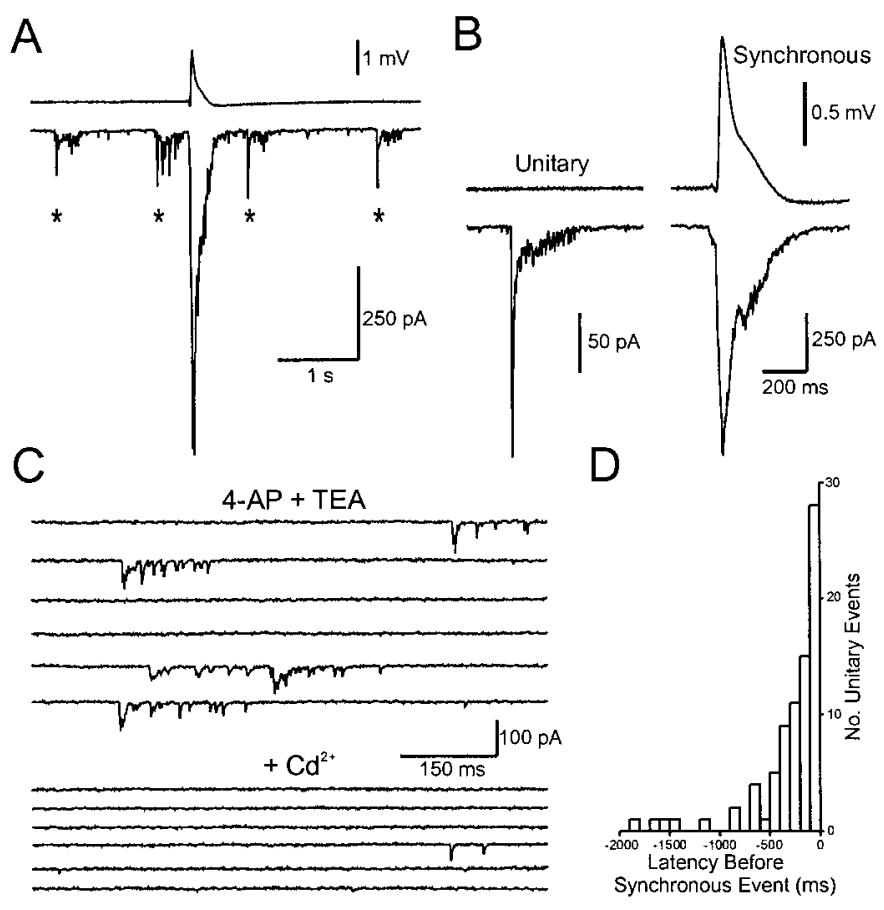

Figure 5. Asynchronous unitary synaptic responses often precede synchronous discharges. $A$, Simultaneous CA 3 c field potential recording (top trace) and voltage-clamp recording from a hilar mossy cell (bottom trace). In addition to the synchronous response in both records, four smaller discharges (asterisks) appear only in the intracellular recording. B, Average unitary responses and synchronous responses from the cell shown in $A$. No field response is observed during the unitary response. $C$, Consecutive sweeps from a hilar mossy cell recording show four unitary spontaneous responses. These responses were not observed without 4-AP and TEA and were blocked by $100 \mu \mathrm{M}$ cadmium. $D$, Histogram of the latency between unitary responses and the next synchronous discharge $(n=80$ unitary responses). Unitary responses occurred most frequently immediately $(<500 \mathrm{msec})$ before a synchronous discharge.

sponses elicited by the combination of 4-AP and TEA persist in TTX-treated slices. The inability of even high concentrations of TTX $(3 \mu \mathrm{M})$ to affect synchronized responses suggests that this result is not attributable to an incomplete blockade of fast $\mathrm{Na}^{+}$ channels. Although it is possible that TTX-resistant $\mathrm{Na}^{+}$channels exist in hippocampal neurons, our recordings demonstrate that lower concentrations of TTX $(1 \mu \mathrm{M})$ were sufficient to block the propagation of fast action potentials in mossy fiber axons. The relatively simple time course of TTX-resistant synchronized responses also differs from the more complex series of afterdischarges commonly observed in hippocampal slices exposed to low concentrations of 4-AP (Avoli et al., 1993; Traub et al., 1995) or $\mathrm{GABA}_{\mathrm{A}}$ receptor antagonists (Miles et al., 1984).

Although the synchronized discharges reported here are distinct from the TTX-sensitive bursts elicited by low concentrations of 4-AP, they may represent one member in a family of $\mathrm{Na}^{+}$-channelindependent synchronization mechanisms. Tetrodotoxin-resistant spontaneous discharges of CA3 pyramidal cells have been reported after repetitive applications of NMDA (Cherubini et al., 1991) or metabotropic receptor agonists (Aniksztejn et al., 1995). Interestingly, these synchronized responses, termed periodic inward currents (PICs), were elicited by glutamate receptor agonists only after a blockade of $\mathrm{K}^{+}$currents by $\mathrm{Cs}^{+}$and either TEA or 4-AP. As with the TTX-resistant discharges reported here, the blockade of $\mathrm{K}^{+}$channels in a population of neurons was required. However,
A

A Evoked
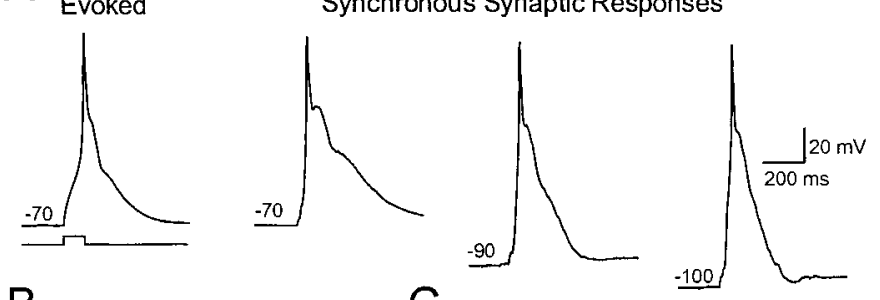

B

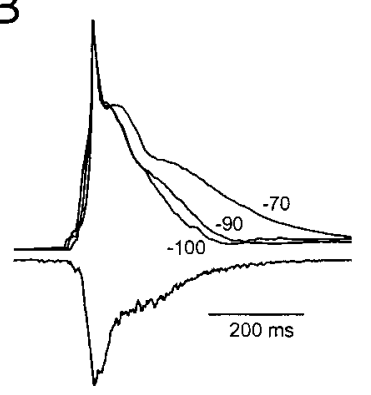

C

TEA

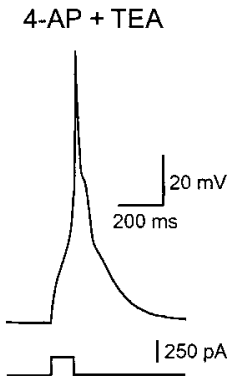

Figure 6. Current-clamp recordings of synchronous responses. $A, \mathrm{Re}-$ generative $\mathrm{Ca}^{2+}$ spike evoked in a CA3 pyramidal cell in response to a short (100 msec) current step in 4-AP (1 mM), TEA (5 mM), and TTX (1 $\mu \mathrm{M})$. Under these conditions the synchronous synaptic input triggered similar intrinsic responses. Both directly and synaptically evoked responses decayed with multiple steps, presumably resulting from the cessation of regenerative calcium current at various dendritic locations. Membrane hyperpolarization minimized these inflections during the recovery to synchronous synaptic input, indicating that spontaneous discharges activate intrinsic voltage-dependent $\mathrm{Ca}^{2+}$ currents in $\mathrm{CA} 3$ pyramidal cells. $B$, Superposition of synchronous synaptic responses at different membrane potentials showing the diminution of inflections during response decays with membrane hyperpolarization (top traces). Responses are normalized and aligned with respect to peak amplitude. For comparison, a field response from CA3c (a different slice) is shown below. $C$, 4-AP reduces the threshold for evoking regenerative $\mathrm{Ca}^{2+}$ spikes. Responses to graded current steps in the presence of TEA $(5 \mathrm{mM})$ and TTX $(1 \mu \mathrm{M})$ are superimposed in the left panel. Responses to the two smallest steps were consistently subthreshold. The threshold for triggering a regenerative $\mathrm{Ca}^{2+}$ spike is reduced after the addition of $1 \mathrm{~mm} 4-\mathrm{AP}$ (right panel).

$\mathrm{K}^{+}$channel blockade alone did not elicit PICs (Cherubini et al., 1991). Although PICs appear to be mediated by non-NMDA glutamate receptors (as are the TTX-resistant discharges reported here), there is an absolute requirement for either NMDA (Cherubini et al., 1991) or metabotropic glutamate (Aniksztejn et al., 1995) receptors to initiate synchronized activity. By contrast, we found that $\mathrm{K}^{+}$channel blockade alone can elicit TTX-resistant synchronous discharges even during a sustained blockade of NMDA receptors.

\section{Activity in CA3 neurons}

We analyzed spontaneous field potentials in different dendritic lamina to determine the source of synchronous synaptic input. Spontaneous field potentials were biphasic in most lamina. The initial negativity was largest in the basal dendrites, consistent with initiation by activity in local recurrent axon collaterals from other CA3 pyramidal cells (Ishizuka et al., 1990; Li et al., 1993). This negativity was followed by a large positive wave, likely reflecting a large dendritic depolarization triggered by the excitatory synaptic input. Interestingly, we never observed an initial negativity in stratum lucidum or stratum radiatum, as would be expected if the intrinsic response was initiated by activity in the mossy fiber or perforant pathway inputs. The propagation of synchronized 
discharges to postsynaptic targets of CA3 pyramidal cells (to hilar and CA1 neurons, but not to dentate granule cells) also is consistent with activity in axons of CA3 pyramidal cells (Ishizuka et al., 1990; Li et al., 1993). However, unlike the pattern of synchronized discharges elicited by disinhibition, the propagation of TTX-resistant activity to CA1 was inconsistent. Field potentials with two negative waves recorded in stratum radiatum in CA1 were clearly distinct from those recorded in CA3. This pattern of synchronized responses could be generated by a network of CA3 pyramidal cells in which axons conveyed activity for only short distances.

\section{Possible mechanism of synchronization}

The most surprising feature of the 4-AP-induced bursts described in this report is their synchronization in the presence of TTX. Cherubini et al. (1991) suggested that TTX-resistant discharges elicited by the repetitive application of NMDA resulted from spontaneous $\mathrm{Ca}^{2+}$ oscillations in presynaptic glutamatergic terminals. We tested this hypothesis by taking advantage of the observation that synchronous synaptic input onto CA3 pyramidal cells can activate both NMDA and non-NMDA glutamate receptors. If the synchronous synaptic input to CA3 neurons is attributable to ectopic $\mathrm{Ca}^{2+}$ spikes in axon terminals, rhythmic NMDA-mediated EPSCs should be evident after a blockade of postsynaptic non-NMDA receptors. We never observed such rhythmic EPSCs in CA3 pyramidal cells held at potentials depolarized enough to relieve the voltage-dependent blockade of NMDA receptors (see Fig. 4). These results suggest that TTXresistant population discharges are not attributable to ectopic $\mathrm{Ca}^{2+}$ spikes in glutamatergic axon terminals. However, it is possible that DNQX also reduced the excitability of presynaptic terminals by preventing the action of endogenous glutamate on presynaptic non-NMDA receptors. However, we found that a blockade of the mainly postsynaptic AMPA receptors with GYKI 52466 completely eliminated synchronized activity, implying that synchronization requires the activation of postsynaptic rather than presynaptic glutamate receptors. We also were unable to restore synchronous discharges halted by non-NMDA receptor antagonists by raising extracellular potassium, a treatment that should enhance presynaptic excitability and facilitate $\mathrm{Ca}^{2+}$ spikes in glutamatergic terminals (Chamberlin et al., 1990; Traub and Dingledine, 1990). The apparent requirement for the activation of postsynaptic glutamate receptors suggests that these discharges are not synchronized by gap junctions or other nonsynaptic interactions.

The cellular mechanism underlying synchronized discharges has been studied most extensively in the disinhibited hippocampus (for review, see Traub and Miles, 1991). Computer simulations (Traub and Wong, 1982, 1983; Traub et al., 1993) point to two critical features of CA3 neurons that are necessary to generate synchronized activity: (1) recurrent excitatory synaptic connections between CA3 pyramidal cells and (2) intrinsic regenerative currents in CA3 pyramidal cells that lead to all-or-none burst discharges. Synchronous discharges occur when the normally subthreshold excitatory connections in CA3 are potentiated or when the intrinsic excitability of CA3 neurons is increased enough to enable burst-to-burst synaptic transmission. This process, termed burst transduction, is thought to be the critical step in generating synchronized discharges and normally is prevented by feedforward inhibition, which acts to limit the amplitude of recurrent EPSPs (Miles and Wong, 1987).

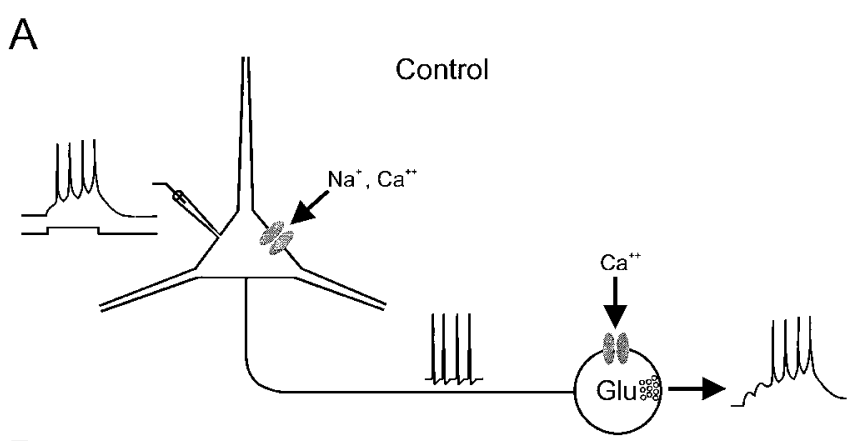

B

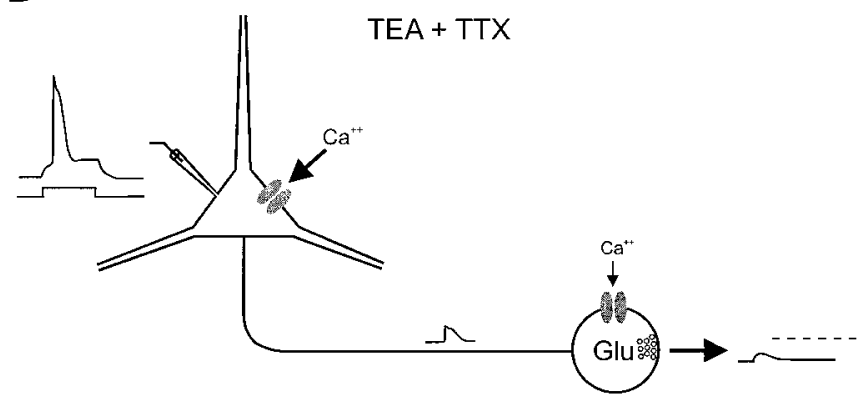

C

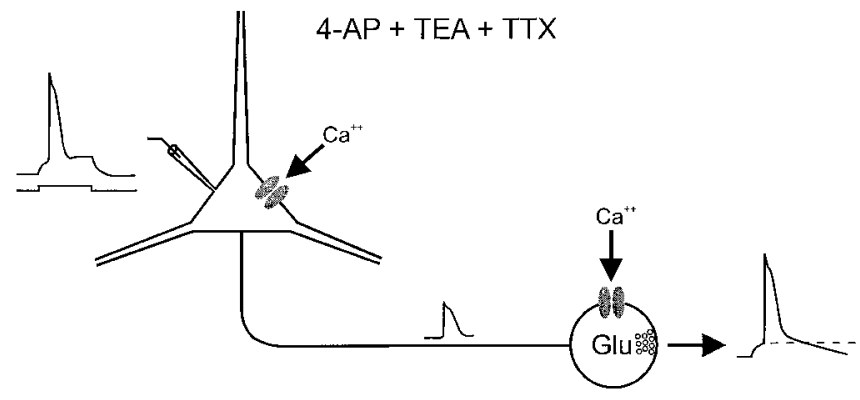

Figure 7. Summary diagram showing a possible mechanism for TTXresistant synchronized discharges. Idealized current-clamp recordings from a CA3 pyramidal cell are shown in the left column; hypothesized intra-axonal and postsynaptic recordings are shown in the middle and right columns, respectively. $A$, Under normal conditions an intrinsic burst discharge evoked by a current injection in the soma of a CA3 neuron leads to a train of glutamatergic EPSPs; these EPSPs can trigger an intrinsic burst response in postsynaptic CA3 neurons with a short delay. $B$, In the presence of TEA and TTX the same stimulus evokes a regenerative $\mathrm{Ca}^{2+}$ spike. Because fast $\mathrm{Na}^{+}$currents are blocked, large somatic depolarizations are not propagated actively through the axons. Rather, the presynaptic terminals are depolarized passively in relation to their electrotonic distance from the soma. At very proximal axon terminals this passive depolarization may trigger local calcium influx and glutamate exocytosis. $C$, After the addition of 4-AP the probability of an intrinsic $\mathrm{Ca}^{2+}$ spike in one CA3 neuron evoking a large enough postsynaptic response to trigger $\mathrm{a} \mathrm{Ca}^{2+}$ spike in another neuron is enhanced greatly because of decreased electrotonic length, increased transmitter release, and reduced $\mathrm{Ca}^{2+}$ spike threshold. The percolation of regenerative $\mathrm{Ca}^{2+}$ spikes through CA3 recurrent axon collaterals may explain the genesis of synchronized discharges in TTX and the high frequency of calcium-dependent unitary synaptic responses.

Is it possible that TTX-resistant discharges are generated by an adaptation of the burst transduction model? Although TTX prevents conduction of $\mathrm{Na}^{+}$-based action potentials in axons, the passive spread of depolarization from the soma-dendrite to the axon would be enhanced after a blockade of $\mathrm{K}^{+}$channels by 4-AP and TEA. If the axonal electrotonic length is decreased sufficiently, the passive depolarization of the axon that accompanies a 
soma/dendritic $\mathrm{Ca}^{2+}$ spike may trigger glutamate release at proximal terminals. This passive depolarization, in combination with the relatively low threshold for triggering a regenerative $\mathrm{Ca}^{2+}$ spike, may provide a basis for $\mathrm{Ca}^{2+}$ spike transduction that does not require fast $\mathrm{Na}^{+}$channels (see Fig. 7). In the same way that the percolation of bursts through a divergent network of CA3 pyramidal cells can become explosive, leading to synchronous burst responses in all CA3 pyramidal cells (Traub and Wong, 1982, 1983), the spread of $\mathrm{Ca}^{2+}$ spikes through networks of CA3 pyramidal cells may underlie TTX-resistant synchronized discharges.

Several lines of evidence suggest that the asynchronous synaptic responses we observed represent the postsynaptic potential after a single regenerative $\mathrm{Ca}^{2+}$ spike in a presynaptic CA3 pyramidal cell. First, these distinct asynchronous responses were not observed in TTX alone but were observed frequently after bath application 4-AP and TEA. Second, while the amplitude of the asynchronous response was much smaller than the synchronous response, the time course of the two responses was similar. Finally, a direct connection between the two types of responses was suggested by the large increase in the frequency of asynchronous responses immediately before a spontaneous synchronous response. Interestingly, a similar increase in the frequency of asynchronous events (either spontaneous EPSPs or unit activity) immediately before synchronized bursts has been described after low doses of 4-AP (Ives and Jefferys, 1990) and high $\mathrm{K}^{+}$(Chamberlin et al., 1990).

This study reports a novel form of synchronized synaptic activity in the hippocampus that does not require the active propagation of fast action potentials. These TTX-resistant synchronized discharges may represent the percolation of regenerative $\mathrm{Ca}^{2+}$ spikes through the same network of recurrent collaterals of CA3 pyramidal cells that supports interictal-like discharges in the disinhibited hippocampus. These TTX-resistant spontaneous discharges may be useful in understanding the cellular basis of synchronized activity in epileptic foci and during development, where excitability normally is enhanced.

\section{REFERENCES}

Aniksztejn L, Sciancalepore M, Ben-Ari Y, Cherubini E (1995) Persistent current oscillations produced by activation of metabotropic glutamate receptors in immature rat CA3 hippocampal neurons. J Neurophysiol 73:1422-1429.

Avoli M, Psarropoulou C, Tancredi V, Fueta Y (1993) On the synchronous activity induced by 4 -aminopyridine in the CA3 subfield of juvenile rat hippocampus. J Neurophysiol 70:1018-1029.

Ayala GF, Dichter M, Gumnit RJ, Matsumoto H, Spencer WA (1973) Genesis of epileptic interictal spikes. New knowledge of cortical feedback systems suggests a neurophysiological explanation of brief paroxysms. Brain Res 52:1-17.

Buckmaster PS, Strowbridge BW, Schwartzkroin PA (1993) A comparison of rat hippocampal mossy cells and CA3c pyramidal cells. J Neurophysiol 70:1281-1299.

Chamberlin NL, Traub RD, Dingledine R (1990) Role of EPSPs in initiation of spontaneous synchronized burst firing in rat hippocampal neurons bathed in high potassium. J Neurophysiol 64:1000-1008.

Cherubini E, Ben-Ari Y, Ito S, Krnjevic K (1991) Persistent pulsatile release of glutamate induced by $N$-methyl-D-aspartate in neonatal rat hippocampal neurons. J Physiol (Lond) 436:531-547.

Chesnut TJ, Swann JW (1988) Epileptiform activity induced by 4-aminopyridine in immature hippocampus. Epilepsy Res 2:187-195.

Chesnut TJ, Swann JW (1990) Suppression of 4-aminopyridine-induced epileptogenesis by the $\mathrm{GABA}_{\mathrm{A}}$ agonist muscimol. Epilepsy Res 5:8-17.
Chittajallu R, Vignes M, Dev KK, Barnes JM, Collingridge GL, Henley JM (1996) Regulation of glutamate release by presynaptic kainate receptors in the hippocampus. Nature 379:78-81.

Collingridge GL, Lester RAJ (1989) Excitatory amino acid receptors in the vertebrate central nervous system. Pharmacol Rev 40:143-210.

Debanne D, Guérineau NC, Gähwiler BH, Thompson SM (1997) Action-potential propagation gated by an axonal $\mathrm{I}_{\mathrm{A}}$-like $\mathrm{K}^{+}$conductance in hippocampus. Nature 389:286-289.

Ishizuka N, Weber J, Amaral DG (1990) Organization of intrahippocampal projections originating from CA3 pyramidal cells in the rat. J Comp Neurol 295:580-623.

Ives AE, Jefferys JGR (1990) Synchronization of epileptiform bursts induced by 4 -aminopyridine in the in vitro hippocampal slice preparation. Neurosci Lett 112:239-245.

Johnston D, Brown TH (1981) Giant synaptic potential hypothesis for epileptiform activity. Science 211:294-297.

Li X-G, Somogyi P, Ylinen A, Buzsáki G (1993) The hippocampal CA3 network: an in vivo intracellular labeling study. J Comp Neurol 338:1-29.

MacVicar BA, Dudek FE (1980) Local synaptic circuits in rat hippocampus: interactions between pyramidal cells. Brain Res 184:220-223.

Michelson HB, Wong RKS (1994) Synchronization of inhibitory neurones in the guinea-pig hippocampus in vitro. J Physiol (Lond) 477:35-45.

Miles R, Wong RKS (1986) Excitatory synaptic interactions between CA3 neurons in the guinea-pig hippocampus. J Physiol (Lond) 373:397-418.

Miles R, Wong RKS (1987) Inhibitory control of local excitatory circuits in guinea-pig hippocampus. J Physiol (Lond) 388:611-629.

Miles R, Wong RKS, Traub RD (1984) Synchronized afterdischarges in the hippocampus: contribution of local synaptic interaction. Neuroscience 12:1179-1189.

Miles R, Traub RD, Wong RKS (1988) Spread of synchronous firing in longitudinal slices from the CA3 region of the hippocampus. J Neurophysiol 60:1481-1496.

Mody I, Lambert JD, Heinemann U (1987) Low extracellular magnesium induces epileptiform activity and spreading depression in rat hippocampal slices. J Neurophysiol 57:869-888.

Muller W, Misgeld U (1991) Picrotoxin- and 4-aminopyridine-induced activity in hilar neurons in the guinea pig hippocampal slice. J Neurophysiol 65:141-147.

Perreault P, Avoli M (1991) Physiology and pharmacology of epileptiform activity induced by 4 -aminopyridine in rat hippocampal slices. J Neurophysiol 65:771-785.

Perreault P, Avoli M (1992) 4-Aminopyridine-induced epileptiform activity and a GABA-mediated long-lasting depolarization in the rat hippocampus. J Neurosci 12:104-115.

Reuveni I, Friedman A, Amitai Y, Gutnick MJ (1993) Stepwise repolarization from $\mathrm{Ca}^{2+}$ plateaus in neocortical pyramidal cells: evidence for nonhomogeneous distribution of $\mathrm{HVA} \mathrm{Ca}^{2+}$ channels in dendrites. J Neurosci 13:4609-4621.

Rodriguez-Moreno A, Herreras O, Lerma J (1997) Kainate receptors presynaptically downregulate GABAergic inhibition in the rat hippocampus. Neuron 19:893-901.

Rutecki PA, Lebeda FJ, Johnston D (1987) 4-Aminopyridine produces epileptiform activity in hippocampus and enhances synaptic excitation and inhibition. J Neurophysiol 57:1911-1924.

Schwartzkroin PA, Prince DA (1978) Cellular and field potentials of epileptogenic hippocampal slices. Brain Res 147:117-130.

Segal M (1987) Repetitive inhibitory postsynaptic potentials evoked by 4-aminopyridine in hippocampal neurons in vitro. Brain Res 414:285-293.

Strowbridge BW (1997a) Action potential-independent synchronized discharges in rat hippocampus mediated by glutamate neurotransmission. Soc Neurosci Abstr 23:2285.

Strowbridge BW (1997b) Glutamate receptors mediate TTX-resistant synchronous activity in the rat hippocampus. J Physiol (Lond) 504P:S11.

Strowbridge BW, Schwartzkroin PA (1996) Transient potentiation of spontaneous EPSPs in rat mossy cells induced by depolarization of a single neuron. J Physiol (Lond) 494:493-510. 
Traub RD, Dingledine R (1990) Model of synchronized epileptiform bursts induced by high potassium in CA3 region of rat hippocampal slice. Role of spontaneous EPSPs in initiation. J Neurophysiol 64:1009-1018.

Traub RD, Miles R (1991) Neuronal networks of the hippocampus. New York: Cambridge UP.

Traub RD, Wong RKS (1982) Cellular mechanism of neuronal synchronization in epilepsy. Science 216:745-747.

Traub RD, Wong RKS (1983) Synchronized burst discharges in disinhibited hippocampal slice. II. Model of cellular mechanism. J Neurophysiol 49:459-471.

Traub RD, Miles R, Jefferys JGR (1993) Synaptic and intrinsic conductances shape picrotoxin-induced synchronized after-discharges in the guinea-pig hippocampal slice. J Physiol (Lond) 461:525-547.

Traub RD, Jefferys JGR, Miles R, Whittington MA, Tóth K (1994) A branching dendritic model of a rodent CA3 pyramidal neurone. J Physiol (Lond) 481:79-95.
Traub RD, Colling SB, Jefferys JGR (1995) Cellular mechanisms of 4-aminopyridine-induced synchronized after-discharges in the rat hippocampal slice. J Physiol (Lond) 489:127-140.

Vignes M, Collingridge GL (1997) The synaptic activation of kainate receptors. Nature 388:179-182.

Voskuyl RA, Albus H (1985) Spontaneous epileptiform discharges in hippocampal slices induced by 4-aminopyridine. Brain Res 342:739-751.

Wong RKS, Prince DA (1978) Participation of calcium spikes during intrinsic burst firing in hippocampal neurons. Brain Res 159:385-390.

Wong RKS, Traub RD (1983) Synchronized burst discharge in disinhibited hippocampal slice. I. Initiation in CA2-CA3 region. J Neurophysiol 49:442-458.

Zorumski CF, Yamada KA, Price MT, Olney JW (1993) A benzodiazepine recognition site associated with the non-NMDA glutamate receptor. Neuron 10:61-67. 